\title{
The effects of habitat fragmentation on the social kin structure and mating system of the agile antechinus, Antechinus agilis
}

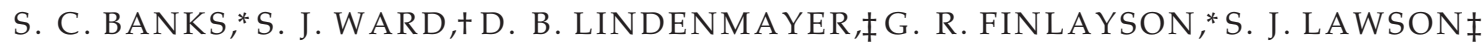 \\ and A. C. TAYLOR* \\ *Centre for Biodiversity: Analysis, Policy and Management, School of Biological Sciences, Monash University, Victoria, 3800 , \\ Australia, †Department of Zoology, The University of Melbourne, Victoria, 3010, Australia, $\ddagger$ Centre for Resource and Environmental \\ Studies, The Australian National University, Canberra, ACT, 0200, Australia
}

\begin{abstract}
Habitat fragmentation is one of the major contributors to the loss of biodiversity worldwide. However, relatively little is known about its more immediate impacts on within-patch population processes such as social structure and mating systems, whose alteration may play an important role in extinction risk. We investigated the impacts of habitat fragmentation due to the establishment of an exotic softwood plantation on the social kin structure and breeding system of the Australian marsupial carnivore, Antechinus agilis. Restricted dispersal by males in fragmented habitat resulted in elevated relatedness among potential mates in populations in fragments, potentially increasing the risk of inbreeding. Antechinus agilis nests communally in tree hollows; these nests are important points for social contact between males and females in the mating season. In response to elevated relatedness among potential mates in fragmented habitat, $A$. agilis significantly avoided sharing nests with opposite-sex relatives in large fragment sites (but not in small ones, possibly due to limited nest locations and small population sizes). Because opposite-sex individuals shared nests randomly with respect to relatedness in unfragmented habitat, we interpreted the phenomenon in fragmented habitat as a precursor to inbreeding avoidance via mate choice. Despite evidence that female $A$. agilis at high inbreeding risk selected relatively unrelated mates, there was no overall increased avoidance of related mates by females in fragmented habitats compared to unfragmented habitats. Simulations indicated that only dispersal, and not nonrandom mating, contributed to inbreeding avoidance in either habitat context. However, habitat fragmentation did influence the mating system in that the degree of multiple paternity was reduced due to the reduction in population sizes and population connectivity. This, in turn, reduced the number of males available to females in the breeding season. This suggests that in addition to the obvious impacts of reduced recruitment, patch recolonization and increased genetic drift, the isolation of populations in habitat patches may cause changes in breeding behaviour that contribute to the negative impacts of habitat fragmentation.
\end{abstract}

Keywords: Antechinus agilis, habitat fragmentation, inbreeding avoidance, mating system, multiple paternity, social kin structure

Received 9 November 2004; revision accepted 7 February 2005

\section{Introduction}

Studies of the impacts of habitat fragmentation commonly focus on community-level effects, or less frequently on effects on the distribution and persistence of populations

Correspondence: S. C. Banks, Fax: 6139905 5613; E-mail: sam.banks@sci.monash.edu.au in remnant habitat and the relevant interpatch processes such as dispersal. Less well known are the effects of fragmentation on within-patch population processes. Consequences of fragmentation such as reduced habitat area, quality, connectivity and population size may impact a range of behaviours at the individual and social group levels (Bjørnstad et al. 1998; Ims \& Andreassen 1999; Stow \& Sunnucks 2004). The mating system is a particularly 
important life history component that is potentially influenced by the effects of habitat fragmentation, including reduced social neighbourhood sizes and restricted dispersal (Cale 2003; Stow \& Sunnucks 2004). The latter might be expected to result in elevated relatedness among potential mates, thereby increasing the risk of inbreeding, which decreases offspring fitness and is a significant contributor to extinction risk in patch populations (Olsson et al. 1996; Keller 1998; Saccheri et al. 1998; Keller \& Waller 2002; Kruuk et al. 2002). Observed responses to elevated inbreeding risk include an increased rate of inbreeding, or inbreeding avoidance by either the selection of less-related mates or the avoidance of mating altogether (Young et al. 2000; Slate \& Pemberton 2002; Stow \& Sunnucks 2004). This suggests that the behavioural response to increased inbreeding risk may influence the severity of the consequences of habitat fragmentation for the species. Mating systems are closely related to other life history traits, and it is likely that their perturbation via fragmentation will have consequences for other behaviours (Clutton-Brock 1989; Ross 2001).

Here we use a replicated study design to investigate the impacts of habitat fragmentation on the social kin structure and mating system of a small semelparous Australian marsupial carnivore, the agile antechinus (Antechinus agilis). This species has an unusual life history in which all individuals are born in early spring (September) and exhibit strong male-biased dispersal and female philopatry as an inbreeding avoidance mechanism (Cockburn et al. 1985). Following postnatal dispersal, A. agilis nest communally in groups of up to 20 individuals, usually in tree hollows (Lazenby-Cohen 1991). In addition to providing enhanced thermoregulation, communal nests are thought to be important points for social contact prior to and during the mating season (Lazenby-Cohen 1991; Cockburn \& Lazenby-Cohen 1992). Mating in A. agilis is promiscuous and occurs in August. Multiple males usually contribute to the litters of 6 to 10 offspring, and male siring success is negatively associated with the genetic similarity between mates (Shimmin et al. 2000; Kraaijeveld-Smit et al. 2002a, b). The benefits to females of mating with multiple males and avoiding genetically similar mates include ensuring complete fertilization, minimizing the risk of using sperm from genetically incompatible males and increasing the genetic diversity within their litters (Kraaijeveld-Smit et al. 2002a; Tregenza \& Wedell 2002). All males die at the end of the mating season but a small proportion of females survive to breed in a second year.

We have studied the demography and dispersal of A. agilis in a landscape dominated by a plantation of exotic Pinus radiata in southeastern Australia and found that although the pine plantation itself does not support resident populations, the species is common in remnant patches of eucalypt forest within the plantation area (Lindenmayer et al. 1999; Banks et al. 2005a). The patch populations are highly fragmented and male dispersal is restricted in the fragmented system such that relatedness among opposite-sex individuals (potential mates) is significantly higher than in unfragmented habitat (Banks et al. 2005b). To explore the impacts of this on the social structure and mating system of $A$. agilis, we addressed the following questions:

1 Do $A$. agilis avoid nesting communally with opposite-sex relatives when male dispersal is restricted by habitat fragmentation?

2 Do female $A$. agilis select unrelated males as sires when the risk of inbreeding is increased due to habitat fragmentation?

The impacts of habitat fragmentation on the size and isolation of local populations may reduce the number of potential mates available to individuals in the breeding season. This may affect the degree of multiple paternity so we also determined whether the number of males contributing to the offspring in each litter was lower in fragmented than unfragmented habitat. We used field and genetic data from sites in fragmented and unfragmented habitat to address these questions. We also compared patterns in large and small fragmented sites to determine whether the species' behavioural responses to fragmentation, such as mate choice, were affected by patch size.

\section{Methods}

\section{Site selection, initial trapping and demographics}

The study was conducted at Buccleuch State Forest (SF), near Tumut, New South Wales, in southeastern Australia. Buccleuch SF is a large (c. 50000 ha) plantation of exotic Pinus radiata, within which there are 192 remnant patches of eucalypt forest ranging in size from less than 1 ha to over 100 ha (Lindenmayer et al. 1999). For this study, we randomly selected 12 sites from those known to be occupied by Antechinus agilis based on previous surveys (Banks et al. 2005a). These included four large and four small eucalypt patches in the pine plantation, as well as four sites in adjacent unfragmented eucalypt forest habitat (see Table 1 for details). Six of these (two from each category) were studied in 2002 and six in 2003.

At the unfragmented sites, we trapped A. agilis for three nights in late June or early July (after postnatal dispersal but prior to the mating season). We used 100 aluminium box traps (Elliott Scientific, Upwey, Victoria, Australia) arranged in four rows ( $25 \mathrm{~m}$ apart) of 25 traps ( $15 \mathrm{~m}$ apart). At each of the fragmented sites we used up to 200 traps over three nights in late June and July to estimate population size and collect DNA samples (see (Banks et al. 2005a). The density of the trapping grids was similar to those in the unfragmented sites so that total trap number varied according to patch area. All captured A. agilis were marked with a 
Table 1 Geographic and demographic data on the sites used for the study and basic radio-tracking and breeding data

\begin{tabular}{|c|c|c|c|c|c|c|c|c|c|c|c|}
\hline $\begin{array}{l}\text { Habitat } \\
\text { context }\end{array}$ & Site & $\begin{array}{l}\text { Patch } \\
\text { area } \\
\text { (ha) }\end{array}$ & $\begin{array}{l}\text { Distance to } \\
\text { nearest } \\
\text { occupied } \\
\text { site }(\mathrm{m})\end{array}$ & $\begin{array}{l}\text { Sample } \\
\text { size }\end{array}$ & $\begin{array}{l}\text { Estimated } \\
\text { population } \\
\text { size and } \\
95 \% \text { CI }\end{array}$ & $\begin{array}{l}\text { Mean } \\
r\end{array}$ & $\begin{array}{l}\text { No. of } \\
\text { radio- } \\
\text { collared } \\
\text { males }\end{array}$ & $\begin{array}{l}\text { No. of } \\
\text { nests } \\
\text { located }\end{array}$ & $\begin{array}{l}\text { No. of } \\
\text { mothers } \\
\text { sampled }\end{array}$ & $\begin{array}{l}\text { Average } \\
\text { minimum } \\
\text { no. of sires } \\
\text { per litter }\end{array}$ & $\begin{array}{l}\text { Proportion of } \\
\text { offspring sired } \\
\text { by resident } \\
\text { males }\end{array}$ \\
\hline \multirow[t]{4}{*}{ Unfragmented } & BSF1 & NA & 0 & 35 & NA & 0.029 & 4 & 5 & 3 & 2.333 & 0.633 \\
\hline & BSF2 & NA & 0 & 49 & NA & 0.014 & 4 & 4 & 8 & 2.875 & 0.640 \\
\hline & WCF2 & NA & 0 & 30 & NA & 0.034 & 4 & 5 & 3 & 3.000 & 0.286 \\
\hline & WCF4 & NA & 0 & 79 & NA & 0.009 & 4 & 9 & 10 & 2.600 & 0.130 \\
\hline \multirow{4}{*}{$\begin{array}{l}\text { Large } \\
\text { patch }\end{array}$} & 1186 & 18.1 & 210 & 90 & $85(77-102)$ & 0.033 & 4 & 6 & 11 & 3.091 & 0.817 \\
\hline & 1902 & 15.3 & 1500 & 19 & $15(12-26)$ & 0.042 & 4 & 4 & 2 & 1 & 1 \\
\hline & $\mathrm{RC}$ & 26.7 & 170 & 36 & $31(25-46)$ & 0.027 & 4 & 4 & 6 & 3 & 0.433 \\
\hline & SBC & 31.1 & 150 & 36 & $33(31-47)$ & 0.038 & 4 & 5 & 11 & 2.727 & 0.646 \\
\hline \multirow{4}{*}{$\begin{array}{l}\text { Small } \\
\text { patch }\end{array}$} & CR1* & 0.7 & 100 & 1 & $1(1-1)$ & NA & 1 & 0 & 0 & NA & NA \\
\hline & CR2 & 0.6 & 100 & 3 & $3(3-3)$ & 0.095 & $1(+19)$ & 1 & 1 & 2 & 0.500 \\
\hline & $\mathrm{BPA}$ & 1.3 & 50 & 15 & $9(8-15)$ & 0.053 & 3 & 2 & 2 & 2.500 & 0.438 \\
\hline & NWR1* & 1.1 & 170 & 6 & $5(5-8)$ & 0.104 & $1(+1 q)$ & 2 & 0 & NA & NA \\
\hline
\end{tabular}

*No nest sharing or paternity data available for these sites.

unique combination of $<2 \mathrm{~mm}$ round clips on the outside of the ear. The ear tissue samples were stored in $99 \%$ ethanol for DNA extraction.

\section{Genetic analysis}

DNA was extracted and all samples genotyped at 15 microsatellite loci as described in Banks et al. (2005a). The gender of sampled pouch young (see below) was determined by amplification of a fragment of the SRY gene using primers designed for the bandicoot SRY gene (Watson et al. 1998) concurrently with the A. agilis microsatellite locus Aa1A (Banks et al. 2005a) as a positive control. Reaction mixtures for sex determination polymerase chain reactions (PCRs) included $2 \mathrm{~mm} \mathrm{MgCl}_{2}, 75 \mathrm{~mm}$ Tris- $\mathrm{HCl}$, $20 \mathrm{~mm}\left(\mathrm{NH}_{4}\right)_{2} \mathrm{SO}_{4}, 0.01 \%$ Tween $20,0.02 \%$ bovine serum albumin, $200 \mu \mathrm{M}$ of dCTP, dGTP and dTTP, $20 \mu \mathrm{M}$ dATP, 5 pmoles of each primer, $0.03 \mu \mathrm{L}$ 33P-labelled dATP at $10 \mathrm{mCi} / \mathrm{mL}, 0.25$ units Taq polymerase (MBI Fermentas), $1 \mu \mathrm{L}$ template DNA and were made up to $10 \mu \mathrm{L}$ with sterile distilled water. An MJ Research PTC-100 thermal cycler was used, with an initial step of $94^{\circ} \mathrm{C}$ for $2 \mathrm{~min}$, followed by 30 cycles of $94^{\circ} \mathrm{C}$ for $20 \mathrm{~s}, 54{ }^{\circ} \mathrm{C}$ for $30 \mathrm{~s}$ and $45 \mathrm{~s}$ at $72{ }^{\circ} \mathrm{C}$ with a final extension step of $72{ }^{\circ} \mathrm{C}$ for $3 \mathrm{~min}$. Products were run on $6 \%$ polyacrylamide sequencing gels and visualized using autoradiography.

Habitat fragmentation effects on social kin structure: Does A. agilis avoid nesting communally with opposite-sex relatives when male dispersal is restricted by habitat fragmentation?

Monitoring nest sharing. In order to identify nest-sharers, we first located communal nests by fitting single-stage radiotransmitters (Sirtrack, New Zealand) to four males at each site (except in the small patches, see Table 1). The radiotransmitters were fitted around their necks with a small cable tie. The collars weighed no more than $5 \%$ of the body mass of any of the animals (25-40 g). We fitted the collars on the final day of grid trapping at each site and used a Telonics TR2 telemetry receiver (Telonics, USA) to locate the male antechinus at rest in communal nests during the middle of each day over a 7-day period. On the final day of radio tracking, we placed 16 traps around each nest to capture and identify nest-sharers. We placed the traps either on platforms attached to the tree trunk or at ground level depending on the height of the nest hollow opening. We opened the traps in the late afternoon prior to commencement of nocturnal foraging, and checked them within $2 \mathrm{~h}$ after sunrise the next day. We trapped at each nest tree on three occasions three nights apart. All individuals trapped at each nest were identified on the basis of their unique ear-notches and previously unsampled individuals were also marked and sampled in this way.

Statistical analysis of nest-sharing data. We first calculated the level of genetic relatedness among individuals at each site and compared between the habitat contexts. Relatedness was estimated at each site using Queller \& Goodnight's (1989) $r$. Allele frequencies for relatedness estimation at each site were calculated from samples collected from that site and all others within a $6-\mathrm{km}$ radius. We wished to use allele frequencies estimated over an equivalent scale to estimate relatedness at each site and $6 \mathrm{~km}$ was the maximum scale that was possible to use for all sites. We used the mean $r$ values at each site to test for differences between the three 
habitat contexts using a single-factor analysis of variance (ANOvA) and post hoc Tukey test in SYSTAT 10 (SPSS Inc.).

We then determined whether $A$. agilis avoided or preferentially shared nests with kin. We recalculated the relatedness values using allele frequencies from only the site in question. For each individual for which we had nestsharing data, we calculated the average relatedness to the $n$ individuals with which that individual was observed to share a nest on at least one occasion. This was compared to a distribution of $r$ values based on randomly sampling $n$ nest-sharers 1000 times from the other individuals sampled at that site using the computer program POPTOOLS 2.6.2 (Hood 2004). The real and randomized values were averaged over individuals and sites and, for each habitat context (unfragmented, large fragments and small fragments) we calculated the $P$ value for the null hypothesis that nest sharing was random with respect to relatedness from the proportion of average $r$ values among random nest-sharers that exceeded the observed value. This test was conducted separately for males and females to test the patterns of relatedness to same-sex and opposite-sex nestsharers. The mean degree of kin avoidance or association by each individual was measured as the difference between the relatedness to observed nest-sharers and the mean relatedness to random nest-sharers (over 1000 simulations). We tested for fragmentation effects on this parameter using two general linear models (GLMs) in SYSTAT 10 (SPSS Inc.). The first model incorporated variation between habitat contexts, sites (nested within habitat contexts) and sampling years. The second GLM incorporated the geographical isolation of each site (the distance to the nearest occupied site in metres such that unfragmented sites scored 0 ), the number of $A$. agilis sampled at that site (sample sizes closely reflected estimated population sizes: Banks et al. 2005a) and the year of sampling. The former GLM tests for an overall effect of fragmentation and potential differences between small and large patches, the latter tests for effects of patch isolation and population size. The year of sampling was included as population sizes were lower in 2003 due to drought and this could affect social and mating behaviour.

Habitat fragmentation effects on mating systems: Do females select unrelated males as sires when the risk of inbreeding is increased due to habitat fragmentation?

Paternity assignment. We trapped females in the third week of October to collect tissue samples from pouch young for genetic paternity analysis. We trapped on two nights at each site with the same trapping grids used previously and collected a small (c. $0.5 \mathrm{~mm}$ ) tissue sample from the tip of the tail of each pouch young from all captured females, as well as an ear sample from any females not previously captured. DNA extraction and genotyping using the SRY marker and 15 microsatellites was conducted as before.

We assigned the paternity of sampled offspring using the computer program CERvUs 2.0 (Marshall et al. 1998). Simulations (10 000 cycles) and paternity assignment were conducted separately for each site. The number of candidate males was the number of males sampled at that site and the neighbouring sites (within approximately $1 \mathrm{~km}$ of the site, as we did not expect males to move between more distant patches, based on radio-tracking and trapping data). The proportion of candidate males sampled was estimated from the mark-recapture population size estimates for those sites in fragmented habitat (Banks et al. 2005a) or set at 0.65 for sites in unfragmented habitat. The proportion of loci genotyped was calculated separately for each site (average $=0.996$ ). The proportion of loci mistyped was estimated at 0.019 based on motheroffspring mismatches. We assumed that each candidate male could have two full siblings among the other candidates. CERVUs 2.0 assigns parentage at a relaxed (80\%) and strict (95\%) confidence level. We did not reject paternity assignments if the most likely sire was only assigned at the $80 \%$ level, but we took into account the number of loci at which the putative offspring-mother-father relationship was not possible. If the observed mismatches were not consistent with genotyping errors at a small number of loci, we considered that the male in question was not the true father and that the true sire had not been sampled.

\section{Do females select unrelated sires in response to habitat fragmentation?}

We determined whether females preferentially selected less-related males as the sires of their offspring (either through behavioural choice or postcopulatory mechanisms such as sperm selection) using the same approach as that used for the nest-sharing data. For each female, the relatedness to the $n$ assigned sires of her offspring was compared to a distribution of $r$ values based on randomly sampling $n$ sires 1000 times from the males sampled at that site. For each female, the degree of inbreeding avoidance was estimated as the difference between the average relatedness to the assigned sires of her offspring and the average relatedness to the randomly simulated sires. We used the same general linear models as for the nest-sharing data to investigate the effects of habitat context, site, year, local population size and patch isolation on the degree of inbreeding avoidance via nonrandom mating and postcopulatory mechanisms. Our null hypothesis could be true either because the inbreeding risk is no greater in fragmented habitat (relatedness of potential mates is no higher) or because females do not respond to an increased risk of inbreeding by mate selection or postcopulatory 
mechanisms. To test the latter hypothesis we calculated the Pearson correlation coefficient between the degree of inbreeding avoidance by each female and her inbreeding risk (the former measured as described above and the latter estimated as the mean relatedness to the randomly simulated males).

\section{Does nonrandom mating or postcopulatory mechanisms contribute to inbreeding avoidance?}

The previously mentioned approach tests only whether the offspring of females were sired by males that were randomly selected (with respect to relatedness) in the same site as females. However, this does not account for the possibility that females may mate with unsampled males, particularly less-related males that visit from other sites. We used a simulation approach to estimate the degree to which dispersal and nonrandom mating contributed to the heterozygosity of offspring and compared these between the habitat contexts. The parameter used was the proportion of typed microsatellite loci homozygous in the offspring $\left(H_{\mathrm{O}}\right)$. Other measures developed to estimate parental similarity may be more accurate (Coltman et al. 1999; Amos et al. 2001), but we found that over the 15 highly variable loci used here, analyses using $H_{\mathrm{O}}$ yielded identical results (data not shown). Furthermore, $H_{\mathrm{O}}$ was a more efficient parameter for the time-consuming computer simulations employed. We compared the $H_{\mathrm{O}}$ values of the sampled offspring with those from simulations of the same number of offspring generated by random selection of sires by the sampled mothers. For each of 1000 simulations conducted using POPTOOLs 2.6.2 (Hood 2004), we used the genotypes of the sampled mothers from each site and randomly selected male genotypes from those of the males known to be at that site prior to the breeding season. For each female, the number of sires randomly selected was equivalent to the number predicted by the software GERUD 1.0, as described in the following section (Jones 2001). Offspring genotypes (the same number as were sampled from each female) were simulated by randomly selecting a paternal and maternal allele for each locus. Average $H_{\mathrm{O}}$ values were calculated for each site and habitat type, and we considered that nonrandom mating significantly contributed to inbreeding avoidance if the mean $\mathrm{H}_{\mathrm{O}}$ of the real offspring was less than that observed in $95 \%$ of the simulations.

We then estimated the contribution of dispersal to inbreeding avoidance by comparing the simulated $H_{\mathrm{O}}$ of offspring from postdispersal random matings (i.e. those described previously) with those of simulated random matings where dispersal had not occurred. The latter simulations were carried out using the genotypes of the offspring sampled at each site as the 'parents' for the simulations, as these represent a predispersal sample (albeit of a different generation). At all sites, we sampled more offspring than adults. Therefore, to simulate random matings among predispersal individuals, we randomly selected the same number of male and female genotypes as in the previous simulations, simulated the new offspring genotypes and calculated the $H_{\mathrm{O}}$ values. This was repeated 1000 times in the same spreadsheet as the postdispersal random matings. We considered that dispersal contributed significantly to inbreeding avoidance if the $H_{\mathrm{O}}$ values based on the postdispersal random mating simulations were lower than those based on the predispersal random matings in more than $95 \%$ of simulations.

We used the same GLMs as used previously to investigate the effects of habitat context, site, year, local population size and patch isolation on the degree to which dispersal and nonrandom mating contributed to inbreeding avoidance, accounting for the variation between mothers.

Habitat fragmentation effects on mating systems: Is the degree of multiple paternities within litters reduced by habitat fragmentation?

Estimating the number of sires per litter. We estimated the minimum number of males that could have sired the litter of each female using two approaches. For the first method, we identified paternal alleles by subtracting the maternal alleles at each locus. The minimum number of males required to contribute to the observed number of paternal alleles at the locus with the most paternal alleles was estimated as $n / 2$, where $n$ is the number of paternal alleles (rounded up to the nearest even number where the number of paternal alleles is odd). For the second approach, we used the computer program GERUD 1.0 (Jones 2001) to estimate the minimum number of paternal multilocus genotypes that could have contributed to the observed multilocus genotypes within a litter. Due to limitations in the GERUD 1.0 program in the number of possible paternal genotypes that can be constructed from the alleles found among the progeny, we could use no more than five loci for any progeny array. However, we conducted the analysis at least twice for each litter using a different set of microsatellites each time (the results were identical for each set of markers).

Statistical analysis of multiple paternity data. We used a GLM to test for effects of habitat context, site (nested within habitat context) and year on the variation in the minimum number of sires per litter (estimated using both methods). The number of offspring per litter was included as an independent variable as this was previously found to be the most important factor influencing the number of sires per litter in unfragmented habitat (Kraaijeveld-Smit et al. 2002a). We also used a GLM to test the effects of patch 
isolation, the number of resident males sampled at that site, year and litter size.

\section{Results}

Habitat fragmentation effects on social kin structure: does Antechinus agilis avoid nesting communally with opposite-sex relatives when male dispersal is restricted by habitat fragmentation?

Monitoring nest sharing. We identified a total of 48 nests, of which 28 were in live trees, 19 in dead stags and one in a small underground burrow. Nest-sharing data could not be obtained from two of the small patch sites. Although Antechinus agilis was radio collared at these sites, and in one case nests was located, the radio collared individuals dispersed and no animal was detected when nest trapping commenced. This also occurred in a fifth small patch site, suggesting that it is common for antechinus to vacate small populations ( $<5$ individuals) prior to the mating season. The average number of nests identified was 5.75 (range 49) at unfragmented sites, 4.75 (range 4-6) in large patches and 1.5 (range 1-2) in small patches. The number of antechinus trapped at a nest in one night ranged from 1 to 11 and averaged $3.6(\mathrm{SD}=0.94)$ at unfragmented sites, 3.1 $(\mathrm{SD}=0.84)$ in large patches and $2.6(\mathrm{SD}=0.53)$ in small patches.

Statistical analysis of nest-sharing data. There was a significant effect of habitat context on average pairwise relatedness within a site (ANOvA $F$ ratio $=14.06, P=0.002$ ). A post hoc Tukey test showed that average pairwise relatedness was significantly higher in the small patches than in the unfragmented sites and large patches $(P=0.002$ and 0.009 , respectively) but average $r$ did not differ between large patches and unfragmented sites $(P=0.487)$. Mean relatedness values are presented in Table 2 .

Figure 1 shows the average $r$ between observed nestsharers compared to $r$ values between simulated random nest-sharers. In the unfragmented sites, female nest-sharers were significantly more related than random (observed $>$ $98.9 \%$ of randomizations) but no significant deviations from random expectations were observed for the other sex categories. In the large patches, the same was observed among females (observed $>99.6 \%$ of randomizations) and a similar, although nonsignificant trend among males (observed $>95.1 \%$ of nest-sharers). Both males and females shared nests with individuals of the opposite sex that were significantly less related than random (males: observed < $1.2 \%$ of randomizations; females: observed $<1.1 \%$ of randomizations). In each of the small patches all females occupied a single nest and there was no significant avoidance of or association with relatives for any of the other categories. Despite the differences between habitat contexts in the
Table 2 Mean pairwise relatedness among agile antechinus within a site for the three habitat contexts

\begin{tabular}{lcccc}
\hline Habitat context & All & Males & Females & Opposite sex \\
\hline Unfragmented & 0.021 & 0.018 & 0.036 & 0.012 \\
Large patch & 0.035 & 0.033 & 0.058 & 0.022 \\
Small patch & 0.084 & 0.047 & 0.238 & 0.044 \\
\hline
\end{tabular}

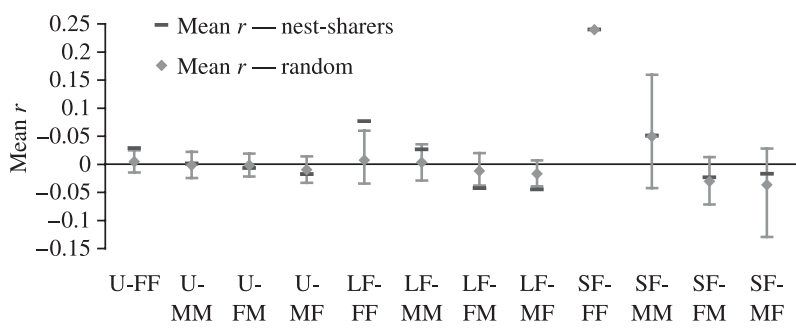

Fig. 1 Mean pairwise relatedness $(r)$ among observed nest-sharing agile antechinus compared to $r$ values among 1000 randomly simulated groups of nest-sharers. The mean and $95 \%$ confidence interval are presented for the randomizations for each category. The category labels ( $x$-axis) U, LF and SF refer to the habitat contexts (unfragmented, large fragments and small fragments). The label FF refers to the relatedness of females to other females with which they shared a nest, MM to the relatedness of males to other males with which they shared a nest, FM to the relatedness of females to the males with which they shared a nest and MF to the relatedness of males to the females with which they shared a nest.

significance of kin association or avoidance among nestsharers, habitat context did not explain a significant component of the variation between sites in the degree of kin association or avoidance $(P>0.05$ for 'habitat context' in all GLMs). Local population size (as estimated by sample size) and year of sampling had no effect $(P>0.05$ for these variables in all GLMs). However, males increasingly avoided female relatives $(P=0.04)$ and associated with male relatives $(P=0.004)$ in communal nests with increasing patch isolation.

Habitat fragmentation effects on mating systems: Do females select unrelated males as sires when the risk of inbreeding is increased due to habitat fragmentation?

Paternity assignment. We sampled 57 females with pouch young and two females with no pouch young. The average litter size per female was $9.23(\mathrm{SD}=1.13$, range $5-11)$ and the average sex ratio (number of females/total) within a litter was $0.46(\mathrm{SD}=0.16)$. Overall, 87 male $A$. agilis were identified as the sires of 288 offspring (out of 527 sampled). There were no instances in which the paternity of a juvenile was not assigned because CERVUs could not distinguish between more than one highly likely male (based on likelihoods and genotype mismatches). This suggested that where no father was assigned to an offspring, the true 
Table 3 General linear model of the proportion of offspring per litter with sires assigned in relation to the number of candidate males at that site, the distance to the nearest occupied site ( 0 for unfragmented sites) and year of sampling $\left(R^{2}=0.168\right)$

\begin{tabular}{lllllr}
\hline Source & Coefficient & Sum of squares & d.f. & Mean square & $F$ ratio \\
\hline Constant & 0.046 & & & & \\
Number of males & 0.019 & 1.156 & 1 & 1.156 & 9.949 \\
Patch isolation & 0.160 & 1.018 & 1 & 1.018 & 8.763 \\
Year & 0.172 & 0.388 & 1 & 0.388 & $\mathbf{0 . 0 0 3}$ \\
Error & & 6.159 & 53 & 0.116 & 0.005 \\
\end{tabular}

father had not been sampled. We used a nested ANOVA and post hoc Tukey test in SYSTAT 10 (SPSS Inc.) to determine whether there were differences between the three habitat contexts in the proportion of offspring in each site to which a resident male had been assigned as the father. Potential variation between years was incorporated into both models with a dummy variable in which sites sampled in 2002 were coded 0 and those sampled in 2003 were coded 1. Habitat context had a significant effect on paternity assignment rate $(P=0.021)$, there was significant variation among sites within each habitat context $(P=0.012)$ but no significant variation between years $(P=0.119)$. The proportion of offspring with sires identified in the same unfragmented site was $0.425(\mathrm{SD}=0.073)$, which was significantly lower than in the large patches $(0.721 \pm 0.165$, Tukey test: $P=$ $0.044)$. The proportion in the small patches $(0.469 \pm 0.063)$ did not differ significantly from the other habitat types ( $P=0.976$ and 0.699 , respectively). A GLM incorporating patch isolation and the number of resident males revealed that the two former variables had significant positive relationships with the average proportion of offspring per litter with resident sires assigned (Table 3).

Do females select unrelated sires in response to habitat fragmentation? The comparison of the relatedness of females to the sires of their offspring is presented in Fig. 2. The average relatedness of females to the sires of their offspring was lower than the mean of the randomized values for the unfragmented sites and large patches. However, the $r$ values were not significantly lower than expected in any of the categories (the proportion of randomized values $\geq$ observed was $83.8 \%$ in unfragmented sites, $63.0 \%$ in large patches and $16.1 \%$ in small patches). The GLM incorporating habitat context, site and year explained no significant variation in the degree of inbreeding avoidance via mate choice and postcopulatory mechanisms (the observed relatedness of females to the sires of their offspring minus the mean relatedness to the randomly simulated sires: ANOvA $F$ ratio $=1.416, P=0.305)$. Likewise, the GLM incorporating patch isolation, local population size and year did not explain a significant proportion of the variation in the degree of inbreeding avoidance via mate choice and postcopulatory

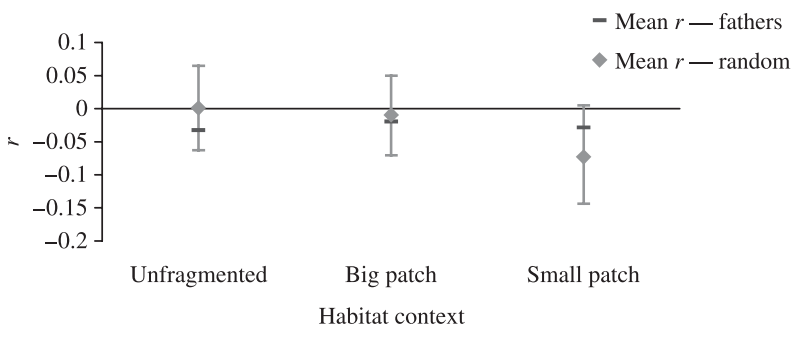

Fig. 2 Mean pairwise relatedness $(r)$ of agile antechinus females to males identified by CERvus as the fathers of their pouch young. Also presented are the mean and $95 \%$ confidence interval of the relatedness of females to randomly selected males based on 1000 simulations for each habitat context.

mechanisms ( $F$ ratio $=0.96, P=0.39)$. However, the offspring of females at high inbreeding risk were generally sired by less related males. The Pearson correlation coefficient of $-0.492(P=0.001)$ shows that the degree to which a female's offspring were sired by males to which she was less related than random was correlated with her average relatedness to randomly selected resident males.

Does nonrandom mating or postcopulatory mechanisms contribute to inbreeding avoidance? When modelled, random matings among postdispersal individuals resulted in significantly lower offspring $H_{\mathrm{O}}$ than random matings among predispersal individuals in all habitat contexts (Table 4). However, mean $H_{\mathrm{O}}$ of the real offspring was not significantly lower than the random mating simulations. This suggests that dispersal, but not nonrandom mating or postcopulatory mechanisms, significantly contributes to inbreeding avoidance. A GLM incorporating habitat context, site and year did not explain significant variation in the simulated contribution of dispersal or nonrandom mating/ postcopulatory mechanisms to inbreeding avoidance (dispersal: ANOvA $F$ ratio $=0.579, P=0.585$; nonrandom mating: $0.404, P=$ 0.682). Likewise, GLMs of patch isolation and sample size did not explain any significant variation between sites in the contribution of either of these mechanisms to inbreeding avoidance (dispersal: $1.164, P=0.366$; nonrandom mating: $0.733, P=0.514)$. 
Table 4 Estimated contributions of dispersal and nonrandom mating to inbreeding avoidance as estimated by the proportion of homozygous loci $\left(H_{\mathrm{O}}\right)$ of offspring. Mean $H_{\mathrm{O}}$ values of the real sampled offspring are presented as well as those based on simulated scenarios of no dispersal and nonrandom mating and dispersal and random mating. P1 represents a test of the null hypothesis that postdispersal random mating simulated $H_{\mathrm{O}}$ values are not lower than predispersal random mating $H_{\mathrm{O}}$ values and shows the proportion of simulated predispersal values lower than the simulated postdispersal values. P2 represents the test of the null hypothesis that the $H_{\mathrm{O}}$ values of the real offspring are not lower than those based on simulated random mating among the adults at that site and shows the proportion of simulated values lower than the observed value

\begin{tabular}{|c|c|c|c|c|c|c|c|c|c|}
\hline & \multicolumn{9}{|c|}{ Mating system } \\
\hline & \multicolumn{3}{|c|}{$\begin{array}{l}\text { No dispersal, random } \\
\text { mating (simulated) }\end{array}$} & \multicolumn{4}{|c|}{$\begin{array}{l}\text { Dispersal, random } \\
\text { mating (simulated) }\end{array}$} & \multicolumn{2}{|c|}{$\begin{array}{l}\text { Dispersal } \\
\text { nonrandom } \\
\text { (mating } \\
\text { real offspring) }\end{array}$} \\
\hline & Mean sim. & $2.5 \% \mathrm{CI}$ & $97.5 \% \mathrm{CI}$ & Mean sim. & $2.5 \% \mathrm{CI}$ & $97.5 \% \mathrm{CI}$ & $\mathrm{P} 1$ & Mean & $\mathrm{P} 2$ \\
\hline Unfragmented & 0.211 & 0.185 & 0.236 & 0.162 & 0.147 & 0.177 & 0.000 & 0.167 & 0.769 \\
\hline Large patch & 0.224 & 0.193 & 0.258 & 0.177 & 0.160 & 0.195 & 0.009 & 0.174 & 0.368 \\
\hline Small patch & 0.275 & 0.210 & 0.323 & 0.178 & 0.147 & 0.212 & 0.007 & 0.210 & 0.968 \\
\hline
\end{tabular}

Table 5 The average number of litters sampled per site, average litter size, average litter sex ratio (number of females/total) and average minimum number of sires per litter as estimated by GERUD 1.0 and the number of paternal alleles per locus for each habitat category. Standard deviations are provided for each value

\begin{tabular}{|c|c|c|c|c|c|}
\hline Habitat context & No. of litters per site & Litter size & Litter sex ratio & Min. sires (no. of alleles) & Min. sires (GERUD) \\
\hline Unfragmented & $6.00 \pm 3.56$ & $9.33 \pm 1.20$ & $0.50 \pm 0.14$ & $2.63 \pm 0.65$ & $2.71 \pm 0.62$ \\
\hline Large patch & $7.50 \pm 4.36$ & $9.20 \pm 1.09$ & $0.44 \pm 0.16$ & $2.70 \pm 0.70$ & $2.80 \pm 0.76$ \\
\hline Small patch & $1.50 \pm 0.71$ & $8.67 \pm 1.15$ & $0.45 \pm 0.3$ & $2.67 \pm 0.58$ & $2.33 \pm 0.58$ \\
\hline
\end{tabular}

Mean offspring $H_{\mathrm{O}}$ was higher in large patches $(0.174$ $\mathrm{SD}=0.026)$ than unfragmented sites $(0.167 \pm 0.012)$, and higher in small patches $(0.210 \pm 0.048)$ than large patches. A GLM revealed significant variation in $H_{\mathrm{O}}$ between the offspring of different mothers $(P=0.001)$, but no variation was explained by habitat context $(P=0.635)$, site $(P=0.190)$ or year $(P=0.085)$. Further, a GLM of the variation between females in average $H_{\mathrm{O}}$ of the real offspring revealed no significant effects of local population size $(P=0.245)$, patch isolation $(P=0.876)$ or the year of sampling $(P=0.079)$.

Habitat fragmentation effects on mating systems: Is the degree of multiple paternities within litters reduced by habitat fragmentation?

The minimum number of sires per litter varied from 1 to 4 for both methods of estimation (Table 5). The statistical analyses presented are based on the minimum number of fathers estimated by GERUD 1.0, but the analyses based on the data using the number of paternal alleles were similar. There was significant variation between sites within the habitat contexts $(P=0.006)$ and there was a significant positive effect of litter size on the number of sires per litter
$(P=0.011)$. However, we found no significant effect of habitat context $(P=0.396)$ or year $(P=0.947)$. Even in the smallest fragment population, CR2, where only one male was known to be present, we found that multiple males had contributed to the litter of the only mother sampled at this site (Table 1). This led us to further investigate the causes of the intersite variation in multiple paternity. The GLM incorporating the number of resident males detected at each site and the distance to the nearest occupied site ( 0 for unfragmented sites) revealed that multiple paternity was positively associated with the number of resident males and negatively associated with patch isolation (Table 6). Multiple paternity may be maintained in small, non-isolated populations by visits by males from nearby patches during the breeding season. For instance, the paternity analyses suggested that multiple paternity of the litter of the female from site CR2 resulted from mating with the sole male in this site, as well as with a male from the nearby site CR1. However, multiple paternity was reduced in more isolated fragments. In the most geographically isolated site (1902), the paternity analyses suggested that no offspring were sired by visiting males (all were assigned to resident sires) and there was no multiple paternity within the litters of the two sampled mothers. 
Table 6 A general linear model of the estimated minimum number of sires per litter in relation to the degree of patch isolation (distance to the nearest occupied patch), the number of males sampled at the site, the number of offspring per litter and the year of sampling $\left(R^{2}=0.349\right)$

\begin{tabular}{lccccc}
\hline Source & Coefficient & Sum of squares & d.f. & Mean square & $F$ ratio \\
\hline Constant & 0.726 & & & & \\
Litter size & 0.172 & 1.992 & 1 & 1.992 & 5.883 \\
Patch isolation & -0.001 & 2.157 & 1 & 2.157 & $\mathbf{0 . 0 1 9}$ \\
Number of males & 0.024 & 1.893 & 1 & 1.893 & $\mathbf{0 . 0 1 5}$ \\
Year & 0.119 & 0.188 & 1 & 0.188 & 0.591 \\
Error & & 17.61 & 52 & 0.339 & 0.556 \\
\hline
\end{tabular}

\section{Discussion}

We expected that reduced local population sizes, increased spatial dispersion of habitat and restricted dispersal in fragmented habitat should have consequences for the social structure and mating system of Antechinus agilis. We found that relatedness among individuals in large patches was higher, but not significantly so, than relatedness among individuals in unfragmented sites and that relatedness among individuals in small patches was significantly higher than both other groups. The effects of increased relatedness on social kin structure were as expected in large patches, in that significant avoidance of opposite-sex kin occurred. The same effect was not evident in small patches, possibly due to the limited numbers of nest trees and nest sharers. Although our predefined habitat context categories did not explain significant variation in multiple paternity, fragmentation reduced the degree of multiple paternity through reduced numbers of resident males and patch isolation. However, no major effects of habitat fragmentation on inbreeding or inbreeding avoidance were detected in this system.

\section{Habitat fragmentation effects on social kin structure}

Communal nests are the focal point for social interactions prior to and during the mating season. Postnatal dispersal by male $A$. agilis results in nest sharing by unrelated individuals of the opposite sex (Cockburn et al. 1985; LazenbyCohen 1991). Our findings in the unfragmented sites confirmed that opposite-sex nest-sharers are unrelated and that this is due to dispersal, as there was no significant avoidance of opposite-sex kin in communal nests. However, where relatedness among potential nest-sharers (i.e. those occupying the same patch) is increased in large patches of fragmented habitat, significant avoidance of opposite-sex kin as communal nest sharers is observed. This finding suggests that the association with unrelated individuals of the opposite sex in communal nests prior to and during the mating season is not simply a consequence of local relatedness structure resulting from dispersal patterns.
Rather, it is a deliberate behaviour to further minimize the risk of mating with relatives. Such behavioural avoidance of related potential mates is not necessary in unfragmented habitat where dispersal results in geographical separation of opposite sex relatives. Mechanisms of kin recognition in A. agilis remain unclear, but in humans and various rodent species, kin recognition operates via preweaning familiarity and / or olfaction-based self-referent phenotype matching (Mateo \& Johnston 2000; Tai et al. 2002; Heth et al. 2003; Weisfeld et al. 2003). In contrast to the pattern in large patches, and despite significantly higher relatedness in small patches, we did not observe any avoidance of opposite-sex kin in communal nests in the small patch sites. The estimated population sizes in the two small patch sites for which we had nest-sharing data were three and nine individuals, respectively. In such small populations, the benefits of nesting with as many other individuals as possible for enhanced thermoregulation may outweigh those of kin avoidance. Further, the number of nest sites may be limiting, because one patch had only a single nest tree used by all individuals and the other had only two nests, one of which was a small underground burrow.

Females in unfragmented sites and large patches associated with same sex kin in communal nests. This may be due to increased tolerance towards kin (Hamilton 1964) or very fine-scale spatial clustering of female relatives due to infrequent dispersal by this sex (Banks et al. 2005b). High relatedness among neighbouring females is common in mammals (e.g. Coltman et al. 2003; Peakall et al. 2003). Even within social groups, females may preferentially associate with kin (Silk et al. 2004). Studies of placental mammals have shown that females obtain fitness benefits, in the form of increased offspring survival, by associating with female relatives (Lambin \& Krebs 1993; Mappes et al. 1995; Lambin \& Yoccoz 1998). We found evidence that the degree of preferential association with same-sex relatives by males increased with patch isolation. Whether this is a deliberate kin selection strategy is unclear, as such a pattern could occur by preferential association with the same unrelated females. 
Habitat fragmentation effects on mating systems: mate choice and inbreeding avoidance

We interpreted the avoidance of opposite-sex kin in large fragmented sites as a precursor to inbreeding avoidance in response to increased inbreeding risk. Avoidance of relatives and selection of mates with dissimilar major histocompatibility complex alleles (Pillay 2002; Bernatchez \& Landry 2003) are important components of mate choice in a number of species (e.g. Bull \& Cooper 1999; Stow \& Sunnucks 2004). We found evidence that pouch young of female $A$. agilis at high inbreeding risk (i.e. that were highly related to the males in the local population) are more likely to be sired by males to which their mother was less related than random. This suggests that females are able to avoid inbreeding by mate selection (either pre- or postcopulation) when necessary. However, this pattern did not hold when the data were combined over individuals and sites. Further, the homozygosity of the real offspring was not significantly lower than what would be expected if mate selection by females were random in any of the habitat contexts, suggesting no increase in the role of inbreeding avoidance as a mate-choice strategy in response to habitat fragmentation. This finding is in contrast to that of Stow \& Sunnucks (2004), who found that in response to elevated relatedness among potential mates caused by habitat fragmentation, there was significant avoidance of related individuals as mates in fragmented sites. It is possible that despite elevated relatedness among potential mates due to habitat fragmentation in Buccleuch SF, the inbreeding risk was not sufficient to induce nonrandom mating with respect to relatedness at the population level. This is supported by the observation that, despite the apparent absence of inbreeding avoidance at the population level, offspring homozygosity was not significantly higher in the fragmented than unfragmented sites. It is likely that where dispersal is adequate to minimize inbreeding, inbreeding avoidance via mate choice does not occur. This was previously observed in the flatworm Dugesia polychroa (Peters \& Michiels 1996) and our simulations of pre- and postdispersal nonrandom mating suggest this is the case in our study system.

The discrepancy in the kin avoidance findings for communal nesting and paternity success may be attributed to the fact that nest sharing is solely a behavioural decision, whereas paternity success is influenced not only by female choice, but also by competition among males and postcopulatory mechanisms influencing siring success. Sperm competitive ability has been shown to be negatively correlated with relatedness (Mack et al. 2002); paternity success in A. agilis is influenced by the level of allele sharing between the male and female (Kraaijeveld-Smit et al. 2002b). However, the timing and order of mating were found to have a much greater effect than allele sharing on paternity success in A. agilis in laboratory experiments (Kraaijeveld-Smit et al. 2002b), and these may have confounded any patterns of inbreeding avoidance via mate choice in the field.

\section{Habitat fragmentation effects on mating systems: multiple paternity}

We found that habitat fragmentation reduced the degree of multiple paternity in A. agilis. However, this was not explained by our predefined habitat context categories (unfragmented sites, large and small patches). Previous studies also reported that male $A$. agilis move large distances between communal nests prior to and during the mating season (Lazenby-Cohen 1991), including across unsuitable habitat (Barnett et al. 1978). We similarly observed A. agilis to travel between habitat fragments during the mating season, with the result that females in small patches would have had access to more potential mates than those present in that patch prior to the rut. The number of males available to females at a site during the breeding season is likely to be a function of the number of resident males at the site and the number of visits by males from further afield, itself a function of the geographical isolation of the patch. Our paternity data support the hypothesis that the more isolated patches receive fewer visits by males from other sites, in that the proportion of litters to which 'resident' males were assigned as the father was significantly positively associated with patch geographical isolation. Kraaijeveld-Smit et al. (2002a) found that variation in the male:female sex ratio between years did not affect the degree of multiple paternity. However, the variation in the available number of males due to habitat fragmentation (local male abundance and patch isolation) is likely to be much greater than that due to temporal sex ratio fluctuations in unfragmented habitat.

The reduction in local population sizes and increased spatial dispersion of habitat due to fragmentation is likely to reduce the size of the local 'social neighbourhood' (Cale 2003). Interpatch movements for breeding also were observed in a North American forest songbird, the hooded warbler (Wilsonia citrina), in which males would regularly traverse cleared areas between forest patches to achieve extra-pair copulations (Norris \& Stutchbury 2001). However, these authors hypothesized that increased isolation of habitat patches could reduce the frequency of these movements and hence the frequency of extra-pair mating. In $A$. agilis, the potential benefits of multiple paternity to females include ensuring complete fertilization, minimizing the risk of using sperm from genetically incompatible males and increasing the genetic diversity within their litters (Kraaijeveld-Smit et al. 2002a; Tregenza \& Wedell 2002). Reduced multiple paternity therefore potentially reduces fecundity and offspring fitness. Further, because a relatively small proportion of $A$. agilis litters are successfully weaned (Lee \& Cockburn 1985), multiple paternity may maximize the proportion of males whose alleles 
are represented in the next generation. Reduced multiple paternity may therefore accelerate genetic drift in small and isolated habitat patches. Significant losses of genetic diversity were not detected in A. agilis populations in any of the fragments surveyed at Buccleuch SF (Banks et al. 2005a), but multiple paternity is common in mammals (Reynolds 1996; Birkhead 2000) and reduced multiple paternity could contribute to the loss of genetic diversity of species in other fragmented habitats.

\section{Implications for species survival in fragmented habitat}

Mating systems are an important component of species' life histories, influencing other behaviours such as sociality and dispersal (Tregenza \& Wedell 2000; Ross 2001). In A. agilis, male-biased dispersal is an inbreeding avoidance strategy (Cockburn et al. 1985), and where this is restriction due to habitat fragmentation, individuals may avoid related members of the opposite sex in communal nests. This finding and those of Stow \& Sunnucks (2004) suggest that species may behaviourally adapt to the ecological changes imposed by habitat fragmentation, such as restricted dispersal, to counter the potential consequences for life history traits such as breeding systems. However, while mate choice may facilitate inbreeding avoidance in fragmented habitat, the overall level of genetic relatedness among individuals within a site will increase in the long-term if dispersal is highly restricted. This may increase the rate of moderate inbreeding and ultimately result in inbreeding depression (Frankham et al. 2002).

We found that both the degree of multiple paternity and the proportion of offspring within a litter to which a sire from the same patch was identified were dependent on patch isolation. This indicates that spatially proximal patches in fragmented habitat are not completely discrete breeding populations. This is supported by the fact that we attempted to monitor nest- sharing and mate choice in five small patches but all individuals in three of these sites disappeared from their patch prior to the breeding season, possibly to nearby larger patches. If populations in small patches are not independent of those in nearby larger patches, they are unlikely to be susceptible to the extinction risks associated with small population size (Caughley 1994; Frankham et al. 2002). The pattern of patch occupancy by $A$. agilis in this system is consistent with this in that the more geographically isolated patches were less likely to be occupied (Banks et al. 2005a). Further, the populations in the most geographically isolated occupied patches show some evidence of 'social isolation'; in the most distant patch population, there was no evidence for multiple paternity or paternity by males from other patches. Although genetic evidence (microsatellite and mitochondrial DNA diversity) suggest that this population was not demographically isolated (Banks et al. 2005a), interpatch move- ments during the breeding season may be shorter than postnatal dispersal distances. Therefore, social isolation may occur over a smaller scale of patch geographical isolation. Patch isolation is considered a major contributor to species' distributions in fragmented habitat due to the negative effects of reduced dispersal on population persistence and patch recolonization (Stacey \& Taper 1992; Thomas et al. 1992; Hanski 1994; Frankham et al. 2002). Our results indicate that in addition to the obvious, more direct impacts of reduced recruitment, patch recolonization and increased genetic drift, the isolation of populations in habitat patches may cause changes in breeding behaviour that contribute to the negative impacts of habitat fragmentation.

\section{Acknowledgements}

Thanks to Jacqueline Devereaux and Joe Banks for their assistance in the field, Chris MacGregor and Dave Rawlins for their hospitality at Tumut, and Peter Temple-Smith for the loan of his radio-tracking equipment. The suggestions of two reviewers improved an earlier version of this manuscript. This study was conducted under Monash University Animal Ethics permit BSCI/2001/10 and New South Wales National Parks and Wildlife Service research permits B2293 (S. Banks) and A2993 (A. Taylor) and was funded by an Australian Research Council Discovery grant.

\section{References}

Amos W, Worthington Wilmer J et al. (2001) The influence of parental relatedness on reproductive success. Proceedings of the Royal Society of London. Series B, Biological Sciences, 268, 20212027.

Banks SC, Finlayson GR, Lawson SJ et al. (2005a) The effects of habitat fragmentation due to forestry plantation establishment on demography and genetic variation in a marsupial carnivore, Antechinus agilis. Biological Conservation, 122, 581-597.

Banks SC, Ward SJ, Lindenmayer DB, Taylor AC (2005b) The effects of habitat fragmentation due to forestry plantation establishment on spatial genotypic structure in a small marsupial carnivore, Antechinus agilis. Molecular Ecology, in press.

Barnett JL, How RA, Humphreys WF (1978) The use of habitat components by small mammals in eastern Australia. Australian Journal of Ecology, 3, 277-285.

Bernatchez L, Landry C (2003) MHC studies in nonmodel vertebrates: what have we learned about natural selection in 15 years? Journal of Evolutionary Biology, 16, 363-377.

Birkhead T (2000) Promiscuity: An Evolutionary History of Sperm Competition. Harvard University Press, Cambridge, Massachusetts.

Bjørnstad ON, Andreassen HP, Ims RA (1998) Effects of habitat patchiness and connectivity on the spatial ecology of the root vole Microtus oeconomus. Journal of Animal Ecology, 67, 127-140.

Bull CM, Cooper SJB (1999) Relatedness and avoidance of inbreeding in the lizard, Tiliqua rugosa. Behavioural Ecology and Sociobiology, 46, 367-372.

Cale PG (2003) The influence of social behaviour, dispersal and landscape fragmentation on population structure in a sedentary bird. Biological Conservation, 109, 237-248.

Caughley G (1994) Directions in conservation biology. Journal of Animal Ecology, 63, 215-244. 
Clutton-Brock TH (1989) Mammalian mating systems. Proceedings of the Royal Society of London. Series B, Biological Sciences, 236, 339372.

Cockburn A, Lazenby-Cohen KA (1992) Use of nest trees by Antechinus stuartii, a semelparous lekking marsupial. Journal of Zoology, London, 226, 657-680.

Cockburn A, Scott MP, Scotts DJ (1985) Inbreeding avoidance and male-biased natal dispersal in Antechinus spp. (Marsupialia, Dasyuridae). Animal Behaviour, 33, 908-915.

Coltman DW, Pilkington JG, Pemberton JM (2003) Fine-scale genetic structure in a free-living ungulate population. Molecular Ecology, 12, 733-742.

Coltman DW, Pilkington JG, Smith JA, Pemberton JM (1999) Parasite-mediated selection against inbred Soay sheep in a free-living island population. Evolution, 53, 1259-1267.

Frankham R, Ballou JD, Briscoe DA (2002) Introduction to Conservation Genetics. Cambridge University Press, Cambridge.

Hamilton WD (1964) The genetical evolution of social behaviour. Journal of Theoretical Biology, 7, 1-16.

Hanski I (1994) Patch-occupancy dynamics in fragmented landscapes. Trends in Ecology E Evolution, 9, 131-135.

Heth G, Todrank J, Busquet N, Baudoin C (2003) Genetic relatedness assessment through individual odour similarities in mice. Biological Journal of the Linnean Society, 78, 595-603.

Hood GM (2004) рортооLs Version 2.6.2. URL http://www.cse. csiro.au/poptools.

Ims RA, Andreassen HP (1999) Effects of experimental habitat fragmentation and connectivity on root vole demography. Journal of Animal Ecology, 68, 839-852.

Jones AG (2001) GERUD 1.0: a computer program for the reconstruction of parental genotypes from progeny arrays using multilocus DNA data. Molecular Ecology Notes, 1, $215-$ 218.

Keller LF (1998) Inbreeding and its fitness effects in an insular population of song sparrows (Melospiza melodia). Evolution, 52, 240-250.

Keller LF, Waller DM (2002) Inbreeding effects in wild populations. Trends in Ecology \& Evolution, 17, 230-241.

Kraaijeveld-Smit FJL, Ward SJ, Temple-Smith PD (2002a) Multiple paternity in a field population of a small carnivorous marsupial, the agile antechinus, Antechinus agilis. Behavioural Ecology and Sociobiology, 52, 84-91.

Kraaijeveld-Smit FJL, Ward SJ, Temple-Smith PD, Paetkau D (2002b) Factors influencing paternity success in Antechinus agilis: last-male sperm precedence, timing of mating and genetic compatibility. Journal of Evolutionary Biology, 15, 100-107.

Kruuk LEB, Sheldon BC \& Merila J (2002) Severe inbreeding depression in collared flycatchers. Proceedings of the Royal Society of London. Series B, Biological Sciences, 269, 1581-1589.

Lambin X, Krebs CJ (1993) Influence of female relatedness on the demography of Townsend's vole populations in spring. Journal of Animal Ecology, 62, 536-550.

Lambin X, Yoccoz NG (1998) The impact of population kinstructure on nestling survival in Townsend's voles, Microtus townsendii. Journal of Animal Ecology, 67, 1-16.

Lazenby-Cohen KA (1991) Communal nesting in Antechinus stuartii (Marsupialia: Dasyuridae). Australian Journal of Zoology, 39, 273-283.

Lee AK, Cockburn A (1985) Evolutionary Ecology of Marsupials. Cambridge University Press, Cambridge.

Lindenmayer DB, Cunningham RB, Pope ML (1999) A large-scale 'experiment' to examine the effects of landscape context and habitat fragmentation on mammals. Biological Conservation, 88, 387-403.

Mack PD, Hammock BA, Promislow DEL (2002) Sperm competitive ability and genetic relatedness in Drosophila melanogaster: similarity breeds contempt. Evolution, 56, 1789-1795.

Mappes T, Ylonen H, Viitala J (1995) Higher reproductive success among kin groups of bank voles (Clethrionomys glareolus). Eco$\log y, 76,1276-1282$.

Marshall TC, Slate J, Kruuk LEB, Pemberton JM (1998) Statistical confidence for likelihood-based paternity inference in natural populations. Molecular Ecology, 7, 639-655.

Mateo JM \& Johnston RE (2000) Kin recognition and the 'armpit effect': evidence of self-referent phenotype matching. Proceedings of the Royal Society of London. Series B. Biological Sciences, 267, 695-700.

Norris RD, Stutchbury BJM (2001) Extraterritorial movements of a forest songbird in a fragmented landscape. Conservation Biology, 15, 729-736.

Olsson M, Gullberg A, Tegelstrom H (1996) Malformed offspring, sibling matings, and selection against inbreeding in the sand lizard (Lacerta agilis). Journal of Evolutionary Biology, 9, 229-242.

Peters A, Michiels NK (1996) Evidence for lack of inbreeding avoidance by selective mating in a simultaneous hermaphrodite. Invertebrate Biology, 115, 99-103.

Pillay N (2002) Father-daughter recognition and inbreeding avoidance in the striped mouse, Rhabdomys pumilio. Mammalian Biology, 67, 212-218.

Queller DC, Goodnight KF (1989) Estimating relatedness using genetic markers. Evolution, 43, 258-275.

Reynolds JD (1996) Animal breeding systems. Trends in Ecology E Evolution, 11, 68-72.

Ross KG (2001) Molecular ecology of social behaviour: analyses of breeding systems and genetic structure. Molecular Ecology, 10, 265-284.

Saccheri I, Kuussaari M, Kankare M, Vikman P, Fortelius W, Hanski I (1998) Inbreeding and extinction in a butterfly metapopulation. Nature, 392, 491-494.

Shimmin GA, Taggart DA, Temple-Smith PD (2000) Sperm competition and genetic diversity in the agile antechinus (Dasyuridae: Antechinus agilis). Journal of Zoology, London, 252, 343-350.

Silk JB, Alberts SC, Altmann J (2004) Patterns of coalition formation by adult female baboons in Amboseli, Kenya. Animal Behaviour, $67,573-582$.

Slate J, Pemberton JM (2002) Comparing molecular measures for detecting inbreeding depression. Journal of Evolutionary Biology, 15, 20-31.

Stacey PB, Taper R (1992) Environmental variation and the persistence of small populations. Ecological Applications, 2, 18-29.

Stow AJ, Sunnucks P (2004) Inbreeding avoidance in Cunningham's skinks (Egernia cunninghami) in natural and fragmented habitat. Molecular Ecology, 13, 443-447.

Tai F, Sun R, Wang T (2002) Does low fecundity reflect kin recognition and inbreeding avoidance in the mandarin vole (Microtus mandarinus)? Canadian Journal of Zoology, 80, 2150-2155.

Thomas CD, Thomas JA, Warren MS (1992) Distributions of occupied and vacant butterfly habitats in fragmented landscapes. Oecologia, 92, 563-567.

Tregenza T, Wedell N (2000) Genetic compatibility, mate choice and patterns of parentage: invited review. Molecular Ecology, 9, 1013-1027. 
Tregenza T, Wedell N (2002) Polyandrous females avoid costs of inbreeding. Nature, 415, 71-73.

Watson CM, Margan SH, Johnston PG (1998) Sex-chromosome elimination in the bandicoot Isoodon macrourus using Y-linked markers. Cytogenetics and Cell Genetics, 81, 54-59.

Weisfeld GE, Czilli T, Phillips KA, Gall JA, Lichtman CM (2003) Possible olfaction-based mechanisms in human kin recognition and inbreeding avoidance. Journal of Experimental Child Psychology, 85, 279-295.

Young AG, Brown ADH, Burray BG, Thrall PH, Miller CH (2000) Genetic erosion, restricted mating and reduced viability in fragmented populations of the endangered grassland herb Rutidosis leptorrhynchoides. In: Genetics, Demography and Viability of Fragmented Populations (eds Young AG, Clarke GM), pp. 335-360. Cambridge University Press, Cambridge.
This study forms part of Sam Banks' PhD thesis on the impacts of habitat fragmentation on the population biology of A. agilis. Andrea Taylor has diverse interests in the application of genetic markers in conservation biology of Australian native fauna, most recently in understanding of population processes accompanying habitat fragmentation. Simon Ward's research interests include natural history and behavioural ecology of small mammals, particularly marsupials, and seabirds. David Lindenmayer's research focuses on large-scale landscape ecology and conservation biology and ways to mitigate human impacts on biodiversity through improved integration of conservation and production. Graeme Finlayson and Sam Lawson have worked on the Tumut fragmentation study and Graeme Finlayson is currently doing a $\mathrm{PhD}$ on reintroduction ecology of Australian native marsupials. 